\title{
MANAJEMEN WIRELESS DENGAN MAPPING SSID ACCESS POINT PADA STMIK LOMBOK
}

\author{
Ahmad Tantoni' ${ }^{1}$, Mohammad Taufan Asri Zaen² \\ ${ }^{1}$ Program Studi Teknik Informatika, STMIK Lombok \\ 2Program Studi Sistem Informasi, STMIK Lombok \\ Jln. Basuki Rahmat No.105 Praya Lombok Tengah 83511 \\ ${ }^{1}$ ahmad.tantoni@students.amikom.ac.id, ${ }^{2}$ opanzain@gmail.com
}

\begin{abstract}
The wireless network at STMIK Lombok is connected to the local server network and the internet with the spread of access points in several buildings. In some parts of the building have different strengths and the access point or wireless signal strengths, some have broad and strong signal coverage, but there are also areas that have limited / weak signal coverage, even no wireless or blank-spot signal. This blank spot can be caused by many obstacles, including walls, tiles, trees, and others.

Based on observations at STMIK Lombok, wireless signal coverage has not been able to cover the entire campus building area; many are unstable and tend to be weak. Therefore, wireless management research was conducted by mapping the SSID access point which is expected to offer/give a solution so that the wireless signal can cover all STMIK Lombok campus buildings.

Wireless management by mapping SSID access points on STMIK Lombok provides a solution for location placement and number of access points to be installed so that the campus area of STMIK Lombok can be covered by wireless networks.
\end{abstract}

Keywords : wireless, wireless network, mapping SSID, access point, MikroTik

\begin{abstract}
Abstrak
Jaringan wireless di STMIK Lombok terkoneksi ke jaringan server lokal dan internet dengan penyebaran access point di beberapa gedung. Di beberapa bagian gedung memiliki kekuatan dan jangkauan sinyal access point atau wireless yang berbeda-beda, ada yang memiliki jangkauan sinyal yang luas dan kuat, namun ada juga area yang memiliki sinyal yang jangkauannya terbatas/lemah, bahkan tidak ada sinyal wireless atau blank-spot. Blank spot ini bisa disebabkan karena banyak penghalang diantaranya tembok, genteng, pohon dan lain-lain.

Berdasarkan observasi di STMIK Lombok, jangkauan sinyal wireless belum mampu mengcover seluruh area gedung kampus, banyak yang tidak stabil dan cenderung lemah. Oleh sebab itu dilakukan penelitian manajemen wireless dengan mapping SSID access point yang diharapkan memberi solusi agar sinyal wireless bisa mengcover semua gedung kampus STMIK Lombok.

Manajemen wireless dengan mapping SSID access point pada STMIK Lombok memberikan solusi penempatan lokasi dan jumlah access point yang akan dipasang agar area kampus STMIK Lombok bisa tercover jaringan wireless.
\end{abstract}

Kata kunci : wireless, jaringan nirkabel, mapping SSID, access point, MikroTik 


\section{Pendahuluan}

STMIK Lombok merupakan sebuah perguruan tinggi swasta yang berada di kabupaten Lombok Tengah dan disahkan oleh Surat Keputusan Menteri Pendidikan Nasional nomor registrasi 201/D/0/2004. STMIK Lombok menggunakan jaringan nirkabel dalam memenuhi kebutuhan akses internet untuk civitas akademika di sekitar kampus.

Jaringan wireless ini terkoneksi ke jaringan server lokal dan ke internet dengan penyebaran access point di beberapa gedung. Di beberapa gedung kampus STMIK Lombok memiliki kekuatan dan jangkauan sinyal access point atau wireless yang berbeda-beda, ada jangkauan sinyal yang luas dan kuat namun juga ada area sinyal yang jangkauannya terbatas/lemah bahkan tidak ada sinyal wireless atau blank-spot karena banyak penghalang diantaranya tembok, genteng, pohon dan lain-lain.

Berdasarkan observasi pada gedung STMIK Lombok, dan penelitian sebelumnya terkait jangkauan sinyal wireless belum mampu mengcover seluruh area gedung kampus, banyak yang tidak stabil dan cenderung lemah [1]. Maka dari itu, dilakukan penelitian manajemen wireless dengan mapping SSID access point STMIK Lombok dan diharapkan memberikan solusi agar sinyal wireless bisa mengcover semua gedung di kampus STMIK Lombok.

\section{Tinjuan Pustaka}

Penelitian yang dilakukan Titahningsih, dkk (2018) tentang Perancangan Penempatan Access Point untuk Jaringan Wifi Pada Kereta Api Penumpang. Penelitian ini memeiliki kesamaan untuk melakukan mapping SSID, penelitian ini dilakukan pada kereta api penumpang sedangkan yang ini dilakukan pada kampus. Motode penyelesaian menggunakan link budget, jumlah access point, jangkauan access point, kapasitas client. Hasil penelitian adalah jumlah minimal access point yang dibutuhkan agar dapat berkerja dengan baik dalam kereta api penumpang adalah 3 access point. Dan untuk penempatan access point akan ditempatkan sejajar ditengah-tengah kereta api penumpang karena dengan posisi ini sinyal dari access point dapat menyebar merata dalam kereta api penumpang. [2]

Penelitian yang dilakukan Wanto, dkk (2018) tentang Analisis dan Pemodelan Posisi
Access Point Pada Jaringan WIFI menggunakan Metode Simulate Annealing. Kesamaan yang diteliti terdapat pada kesamaan untuk menentukan letak terbaik penempatan access point supaya bisa mengcover semua tempat yang diinginkan. Motode penyelesaian yang digunakan adalah simulate annealing. Penghitungan terhadap parameter-parameter yang dicari yaitu menentukan fungsi evaluasi atau fungsi objektif dari simulate annealing yang dihasilkan dari fungsi jarak, penghalang, ketinggian transmitter, pengguna, tipe dan merk access point dari hasil pengukuran dilapangan dan melakukan pengujian terhadap 1 (dua) buah perangkat access point yang diletakkan dalam ruang 1 (satu) dimensi dengan sistem propagasi Line Of Sight (LOS) dan Non Line Of Sight (NLOS). Hasil penelitian adalah metode yang dikembangkan dalam penelitian ini memberikan hasil optimisasi yang lebih baik pada propagasi LOS untuk gedung 1 lantai 4 AMIK TUNAS BANGSA Pematangsiantar menghasilkan presentase coverage area terbaik. Dengan hasil RSSI di antara $-50 \mathrm{dBm} \mathrm{s} / \mathrm{d}-60 \mathrm{dBm}$ yang masuk dalam kategori kekuatan sinyal Excellent. [3]

Penelitian yang dilakukan Satwika dan Sukafona (2018) tentang Analisis Coverage dan Quality of Service Jaringan WIFI 2,4 GHz Di STMIK STIKOM Indonesia. Kesamaan yang diteliti terdapat tujuan yang sama untuk mengcover seluruh area pancaran sinyal wireless, akan tetapi penelitian yang dilakukan ini sampai ke pengujian QoS. Motode penyelesaian penelitian ini meliputi studi literatur, identifikasi masalah, pengukuran kualitas sinyal WiFi, pengukuran QOS jaringan WiFi, analisis kuat sinyal dan performansi jaringan WiFi. Hasil penelitian ini kondisi coverage sinyal berdasarkan kuat sinyal yang dipancarkan adalah secara keseluruhan sudah tercover jaringan WiFi, namun ada beberapa area yang tercover sinyal dengan kualitas sinyal yang sangat rendah. [4]

Penelitian yang dilakukan Puspitasari dan Pulungan (2018) tentang Optimisasi Penempatan Posisi Access Point pada Jaringan WIFI Menggunakan Metode Simulated Annealing. Kesamaan yang diteliti untuk melakukan mapping SSID, metode penyelesaian yaitu teknik pengumpulan data, pemodelan sistem berdasarkan kondisi access point sebenarnya dan pemodelan sistem berdasarkan metode simulated annealing. Hasil penelitian 
menyimpulkan metode yang dikembangkan memberikan hasil optimisasi yang lebih baik dibandingkan dengan perencanaan awal. Dan hasil pengujian dengan pemodelan sistem menggunakan metode simulated annealing dengan nilai threshold level daya sebesar -30 dBm. [5]

\subsection{WLAN (Wireless Local Area Network)}

WLAN (Wireless Local Area Network) merupakan salah satu jaringan komputer yang memanfaatkan gelombang radio sebagai media transmisi data. Informasi data elektronik ditransfer dari satu komputer ke komputer lain melalui gelombang radio. [6]

\subsection{Wi-Fi (Wireless Fidelity)}

Wi-Fi (Wireless Fidelity) merupakan sekumpulan standar yang digunakan untuk jaringan lokal nirkabel (WLAN). Spesifikasi yang mendasari adalah spesifikasi IEEE 802.11 spesifikasi ini terus dikembangkan hingga muncul banyak standar. Saat ini, spesifikasi wifi memiliki empat standar yaitu: 802.11a, 802.11b, 802.11g, dan 802.11n. [7]

\subsection{Penukuran Kuat sinyal}

Kualitas sinyal didasarkan pada sejumlah faktor, termasuk daya output dari transmitter sensitivitas penerima, path loss dari pemancar ke penerima. Kekuatan sinyal dinyatakan dalam satuan desibel (dB), karena tingkat daya rendah, dan redaman ruang bebas. RSSI menyatakan bahwa nilai kualtas sinyal semakin besar menadakan kualitas sinyalnya lemah dan sebaliknya semakin dekat dengan jumlah nol maka kualitas sinyalnya semakin kuat. [8]

\subsection{Access Point}

Access point adalah perangkat jaringan yang digunakan untuk menghubungkan koneksi beberapa peralatan jaringan wireless. Access point juga berfungsi mengirim dan menerima data menggunkan jaringan wireless.

\subsection{Channel 2,4Ghz}

Penentuan channel yang tepat sangat penting dilakukan agar tidak terjadi overlap atau tumpang tindih dengan jaringan wireless lainnya. Secara lengkap gambaran interference yang akan terjadi antar channel dapat dilihat pada gambar 1 berikut ini. [9]

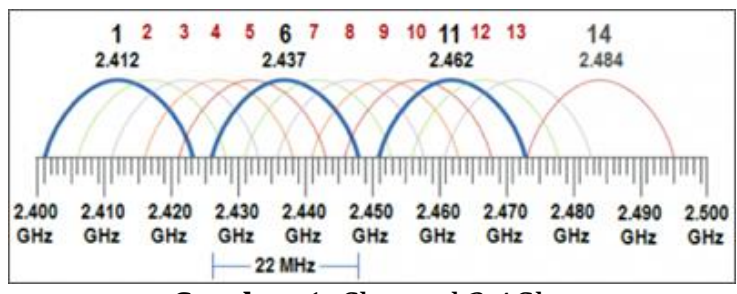

Gambar 1. Channel 2,4Ghz

\subsection{RSSI (Received Signal Strength Indicator)}

RSSI (Received Signal Strength Indicator) sebagai indeks yang menunjukkan kekuatan sinyal yang diterima pada antarmuka antena, dapat digunakan untuk menganalisis sinyal yang diterima dari BTS. Daftar pembagian kualitas jaringan wireless berdasarkan kekuatan sinyalnya pada tabel 1 sebagai berikut: [8] Tabel 1. Kualitas kekuatan sinyal

\begin{tabular}{|c|c|}
\hline Kualitas & Kuat Sinyal $\mathbf{( d B m})$ \\
\hline Exceptional & Better than -40 \\
\hline Very Good & -40 to -55 \\
\hline Good & -55 to -70 \\
\hline Marginal & -70 to -80 \\
\hline $\begin{array}{c}\text { Intermittent to No } \\
\text { Operation }\end{array}$ & -80 and beyond \\
\hline
\end{tabular}

\subsection{Software Ekahau HeatMapper}

Ekahau heatmapper merupakan software yang digunakan untuk melakukan pemetaan area jangkauan dari sinyal access point berdasarkan denah gedung atau lokasi. Hasil pemetaan ini nantinya akan membentuk suatu coverage area dari access point yang terdeteksi, ditandai dengan warna yang muncul pada denah atau lokasi tersebut.

Software Ekahau HeatMapper ini gratis, mudah digunakan, mempermudah dalam pemetaan sinyal, mampu mendeteksi access point dari area lain, hasil dari pemetaan detail dan akurat. Software ini mampu menampilkan access point yang terdeteksi berdasarkan signal, SSID, mac, channel dan security. Detail dari masing-masing access point dapat dilihat secara langsung melalui fitur-fitur diatas atau di tab sebelah kiri. Hasil dari mapping hanya bisa di save kedalam gambar .jpeg atau .png dikarenakan fitur yang tersedia untuk menyimpan hasil hanya take screenshoot, capture warna yang dihasilkan tidak hanya berasal dari satu access point tetapi ada interferensi dari sinyal access point yang terdeteksi di area tersebut. 
Keterangan kekuatan sinyal menggunakan software Ekahau HeatMapper sebagai berikut:

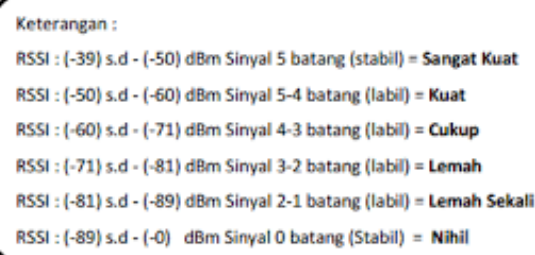

Gambar 2. Keterangan kekuatan sinyal

\section{Metodologi Penelitian}

Metodologi penelitian yang digunakan sebagai berikut:

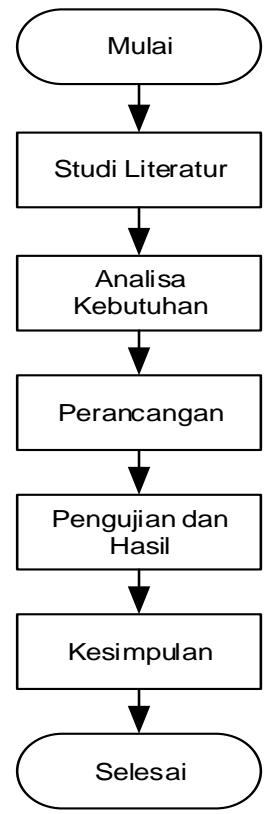

Gambar 3. Metodologi Penelitian

Gambar 3 menjelaskan alur langkah langkah yang akan dilakukan dalam pengerjaan tugas akhir ini. Yang pertama dilakukan studi literature untuk mempelajari dan memahami konsep yang terkait dalam perancangan. Yang kedua melakukan analisis kebutuhan untuk mengidentifikasi kebutuhan dalam perancangan ini, hardware yang digunakan pada analisis mapping wireless ini adalah produk mikrotik dengan seri RB951ui-2hnd. Yang ketiga dilakukan perancangan dan perhitungan berdasarkan hasil dari analisis kebutuhan. Yang keempat dilkakukan pengujian sesuai dengan hasil dari perancangan dan perhitungan dan yang terakhir akan ditarik kesimpulan berdasarkan hasil dari pengujian.

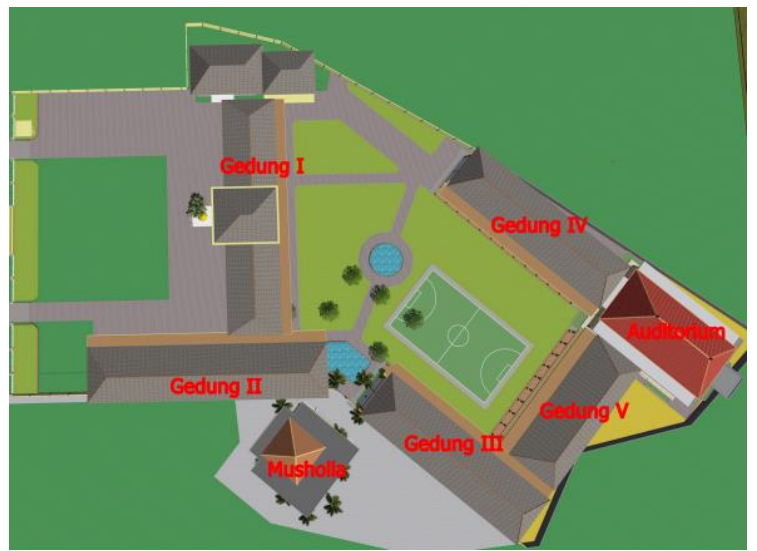

Gambar 4. Denah kampus

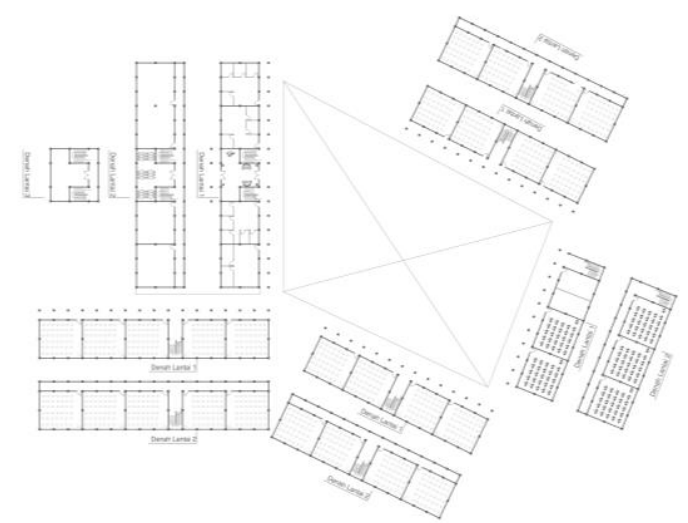

Gambar 5. Denah Ruangan Kampus

a. Gedung 1

Denah gambar ruangan pada gedung 1 lantai 1 sebagai berikut:

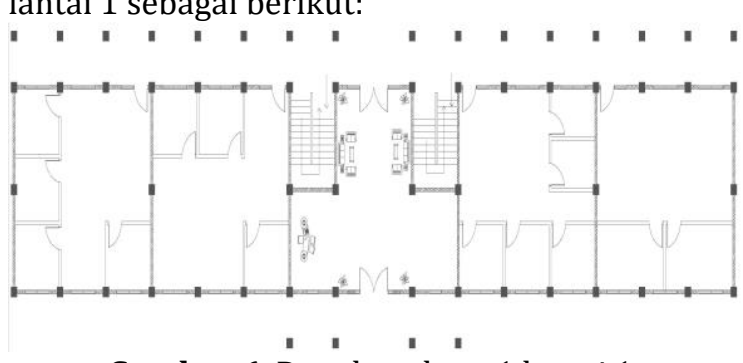

Gambar 6. Denah gedung 1 lantai 1

Denah gambar ruangan pada gedung 1 lantai 2 sebagai berikut:

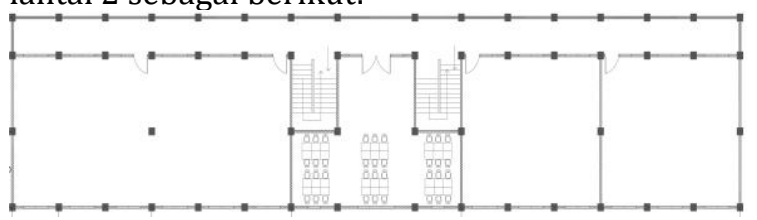

Gambar 7. Denah gedung 1 lantai 2 
Pada gambar 6 terdapat ruang Prodi, Akademik, lobi, Ketua/yayasan dan LPPM, sedangkan pada gambar 7 terdapat ruang untuk seminar

\section{b. Gedung 2}

Denah gambar ruangan pada gedung 2 lantai 1 sebagai berikut:

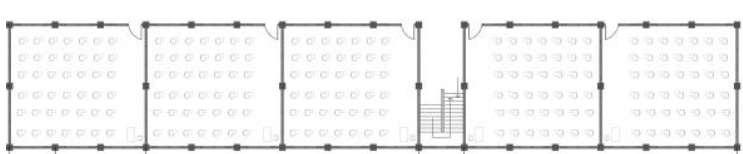

Gambar 8. Denah gedung 2 lantai 1

Denah gambar ruangan pada gedung 2 lantai 2 sebagai berikut:

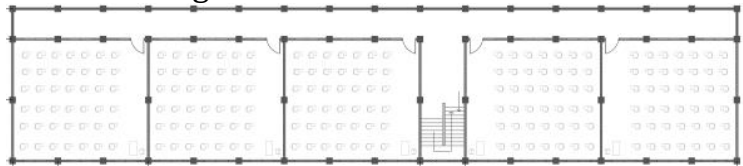

Gambar 9. Denah gedung 2 lantai 2

Pada gambar 8 terdapat 5 ruang kelas sedangkan pada gambar 9 Terdapat 5 ruang kelas

c. $\quad$ Gedung 3

Denah gambar ruangan pada gedung 3 lantai 1 sebagai berikut:

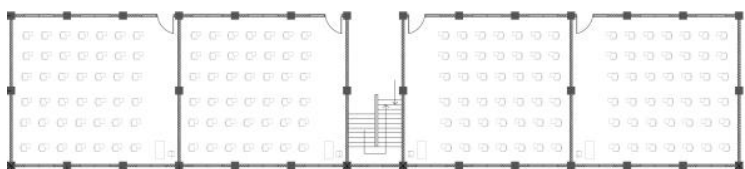

Gambar 10. Denah gedung 3 lantai 1

Denah gambar ruangan pada gedung 3 lantai 2 sebagai berikut:

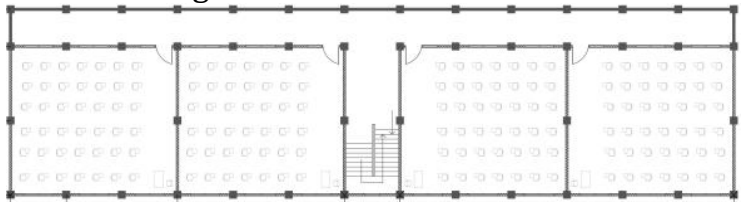

Gambar 11. Denah gedung 3 lantai 2

Pada gambar 10 terdapat 4 ruang kelas sedangkan pada gambar 11 terdapat 4 ruang kelas

\section{Hasil dan Pembahasan}

Bagian Hasil dan Pembahasan merupakan bagian yang memuat semua temuan ilmiah yang diperoleh sebagai data hasil penelitian. Bagian ini diharapkan memberikan penjelasan ilmiah yang secara logis dapat menerangkan alasan diperolehnya hasil-hasil tersebut yang dideskripsikan secara jelas, lengkap, terinci, terpadu, sistematis, serta berkesinambungan.

a. Gedung 1

Hasil mapping SSID pada gedung 1 dengan penempatan 2 access point sebagai berikut:

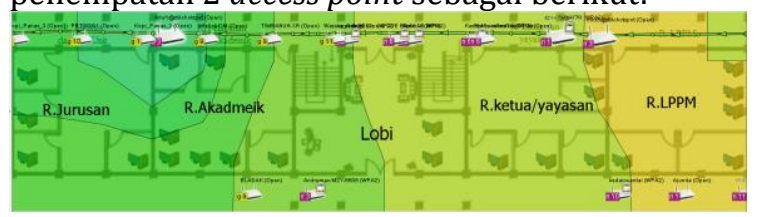

Gambar 12. Hasil mapping SSID mhs1@stilohotspot

Gambar 12 menunjukkan hasil mapping SSID mhs1@stilohotspot yang access pointnya ditempatkan ditengah ruang jurusan dan ruang akademik. Dilihat dari gambar diatas menunjukkan sinyal wireless yang lemah pada ruang ketua/yayasan dan ruang LPPM.

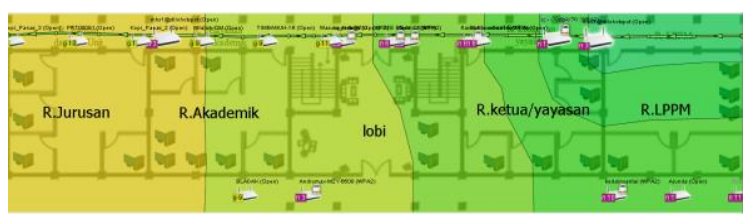

Gambar 13. Hasil mapping SSID mhs2@stilohotspot

Gambar 13 menunjukkan hasil mapping SSID mhs2@stilohotspot yang access pointnya ditempatkan ditengah ruang ketua/yayasan dan ruang LPPM. Dilihat dari gambar diatas menunjukkan sinyal wireless yang lemah pada ruang jurusan dan ruang akademik.

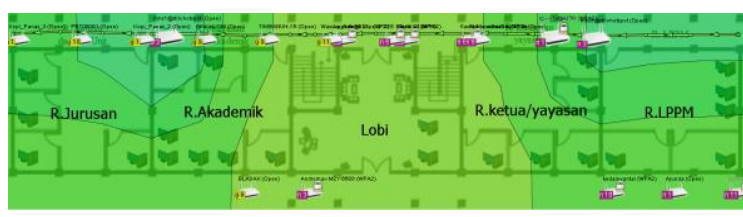

Gambar 14. Gabungan hasil mapping SSID mhs1@stilohotspot dan SSID mhs2@stilohotspot

Gambar 14 menunjukkan gabungan hasil mapping SSID mhs1@stilohotspot dan SSID mhs2@stilohotspot. Dilihat dari gambar diatas menunjukkan kekuatan sinyal wifi sudah tersebar pada semua ruangan. 
b. Gedung 2

Hasil mapping SSID pada gedung 2 dengan penempatan 3 access point sebagai berikut:

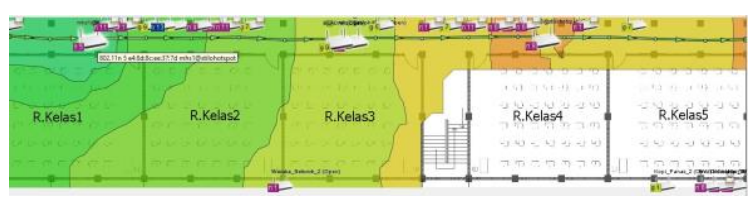

Gambar 15. Hasil Hasil mapping AccessPoint1

Gambar 15 menunjukkan hasil mapping AccessPoint1 ditempatkan ditengah R. Kelas 1 dan R. Kelas2. Dilihat dari gambar diatas menunjukkan sinyal wireless yang lemah pada $\mathrm{R}$. Kelas 3, R. Kelas 4 dan R. Kelas 5.

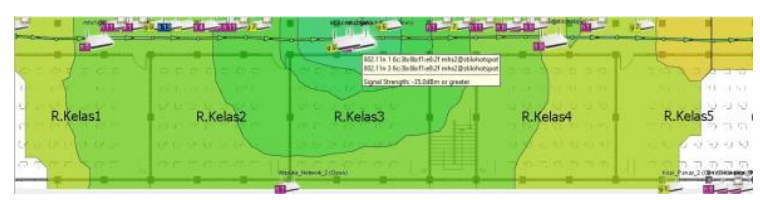

Gambar 16. Hasil mapping AccessPoint2

Gambar 16 menunjukkan hasil mapping AccessPoint2 ditempatkan ditengah R. Kelas3. Dilihat dari gambar diatas menunjukkan sinyal wireless yang lemah pada R. Kelas 1 dan R. Kelas 5.

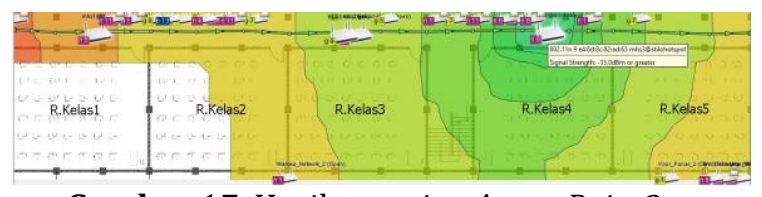

Gambar 17. Hasil mapping AccessPoint3

Gambar 17 menunjukkan hasil mapping AccessPoint3 ditempatkan ditengah R. Kelas 4. Dilihat dari gambar diatas menunjukkan sinyal wireless yang lemah pada R. Kelas1, R. Kelas 2 dan R. Kelas 5.

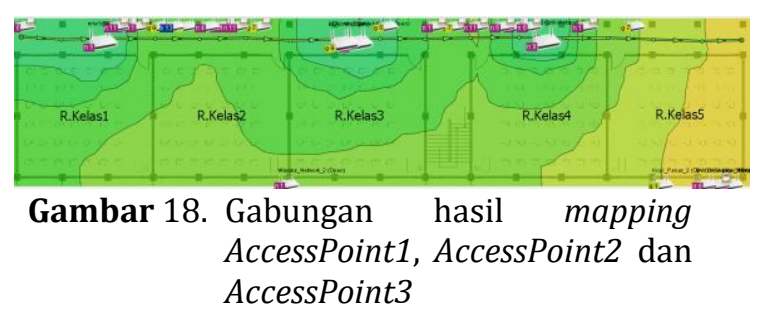

Gambar 18 menunjukkan gabungan hasil mapping AccessPoint1, AccessPoint2 dan AccessPoint3. Dilihat dari gambar diatas menunjukkan kekuatan sinyal wifi sudah tersebar pada semua ruangan.

c. Gedung 3 dan gedung 4

Hasil mapping SSID pada gedung 3 dan gedung 4 dengan masing-masing penempatan 2 access point sebagai berikut:

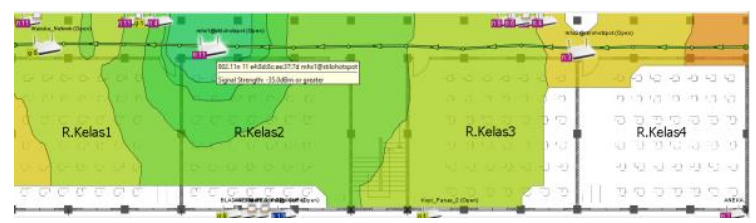

Gambar 19. Hasil mapping SSID mhs1@stilohotspot

Gambar 19 menunjukkan hasil mapping mhs1@stilohotspot ditempatkan ditengah R. Kelas1 dan R. Kelas 2. Dilihat dari gambar diatas menunjukkan sinyal wireless yang lemah pada R. Kelas 3 dan R. Kelas 4.

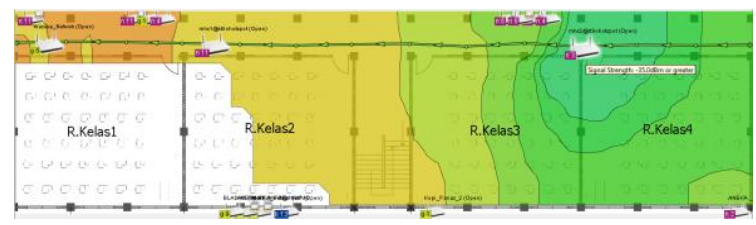

Gambar 20. Hasil mapping SSID mhs2@stilohotspot

Gambar 20 menunjukkan hasil mapping mhs2@stilohotspot ditempatkan ditengah R. Kelas 3 dan R. Kelas 4. Dilihat dari gambar diatas menunjukkan sinyal wireless yang lemah pada R. Kelas 1 dan R. Kelas 2.

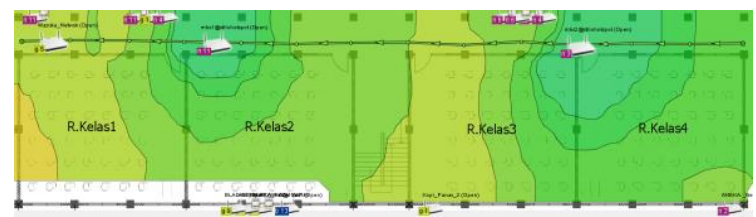

Gambar 21. Gabungan hasil mapping SSID mhs1@stilohotspot dan SSID mhs2@stilohotspot

Gambar 21 menunjukkan gabungan hasil mapping SSID mhs1@stilohotspot dan SSID mhs2@stilohotspot. Dilihat dari gambar diatas menunjukkan kekuatan sinyal wifi sudah tersebar pada semua ruangan. 


\section{Kesimpulan dan saran}

Kesimpulan dari penelitian ini adalah pada gedung 1 ditempatkan perangkat access point sebanyak 2 unit. Pada gedung 2 ditempatkan perangkat access point sebanyak 3 unit. Pada gedung 3 dan gedung 4 ditempatkan perangkat access point sebanyak 2 unit.

Saran penelitian ini adalah menggunakan perangkat jaringan dengan power wireless yang berbeda dan bisa menggunakan software mapping SSID yang berbeda untuk pengujian.

\section{Daftar Pustaka:}

[1] F. Husni and M. T. A. Zaen, "Implementasi Internal Wireless Roaming Menggunakan MikroTik Wireless Distribution System (WDS) Pada STMIK Lombok," JIRE (Jurnal Informatika \& Rekayasa Elektronika), vol. 1, no. 1, pp. 38-43, 2018.

[2] P. Titahningsih, R. Primananda, and S. R. Akbar, "Perancangan Penempatan Access Point untuk Jaringan Wifi Pada Kereta Api Penumpang," J. Pengemb. Teknol. Inf. dan Ilmu Komput. Univ. Brawijaya, vol. 2, no. 5, pp. 2008-2015, 2018.

[3] A. Wanto, J. T. Hardinata, H. F. Silaban, and W. Saputra, "Analisis Dan Pemodelan Posisi Access Point Pada Jaringan Wi-Fi Menggunakan Metode Simulate Annealing," J-SAKTI Jurnal Sains Komput. dan Inform., vol. 1, no. 1, p. 134, 2018.

[4] I. K. S. Satwika and I. M. Sukafona, "Analisis Coverage Dan Quality Of Service Jaringan WiFi 2,4 GHz Di STMIK STIKOM Indonesia," J. Resist. (Rekayasa Sist. Komputer), vol. 1, no. 1, pp. 1-7, 2018.
[5] N. F. Puspitasari and R. Pulungan, “Optimisasi Penempatan Posisi Access Point pada Jaringan Wi-Fi Menggunakan Metode Simulated Annealing," Creat. Inf. Technol. J., vol. 2, no. 1, p. 51, 2018.

[6] M. Syafrizal, Pengantar Jaringan Komputer. Yogyakarta: Penerbit Andi, 2005.

[7] W. Kurniawan, Jaringan Komputer. Yogyakarta: Penerbit Andi, 2007.

[8] I. Veris, Veris Aerospond Wireless Sensors : Received Signal Strength Indicator (RSSI). 2013.

[9] E. Z. Zam, Cara Mudah Membuat Jaringan Wireless. Jakarta: PT Elex Media Komputindo, 2014.

[10] Bakti, W., Imtihan, K., \& Pardiansyah, A. S. (2018). Proxy Server dan Management Bandwidth Jaringan Komputer Menggunakan Mikrotik RB952Ui5ac2nD (Studi Kasus MA Ishlahul Ikhwan Nahdlatul Wathan Mispalah Praya). Jurnal Informatika dan Rekayasa Elektronik, 1(1), 44-49.

[11] Fadli, S., \& Imtihan, K. (2018). ANALISIS DAN PERANCANGAN SISTEM ADMINISTRASI DAN TRANSAKSI BERBASIS CLIENT SERVER. Jurnal Informatika dan Rekayasa Elektronik, 1(2), 7-14.

[12] Supriadi, D., Fahmi, H., \& Imtihan, K. (2018). ANALISA DAN PERANCANGAN INFRASTRUKTUR JARINGAN WIRELESS LOCAL AREA NETWORK (WLAN) PADA DINAS PERINDUSTRIAN DAN PERDAGANGAN KABUPATEN LOMBOK TENGAH. Jurnal Informatika dan Rekayasa Elektronik, 1(2), 1-6. 